\title{
Efeito da temperatura ambiente e da restrição alimentar protéica ou energética sobre o ganho de peso e crescimento ósseo de frangos de corte
}

\author{
[Effect of environmental temperature and protein or energy restriction on body weight gain and \\ broiler chicken bone growth] \\ E.R.L. Pelicano, F.E.M. Bernal, R.L. Furlan*, E.B. Malheiros, M. Macari \\ Faculdade de Ciências Agrárias e Veterinárias \\ Via de Acesso Prof. Paulo Donato Castellane, s/n \\ 14884-900 - Jaboticabal, SP
}

\begin{abstract}
RESUMO
Avaliou-se o efeito da restrição alimentar qualitativa, protéica ou energética sobre o ganho de peso e desenvolvimento ósseo de frangos criados em diferentes temperaturas ambientes. O delineamento experimental foi inteiramente ao acaso, com os tratamentos em um esquema fatorial $3 \times 3$, com os fatores: restrição alimentar $\left(\mathrm{R}_{0}=\right.$ ad libitum; $\mathrm{R}_{1}=$ restrição energética; $\mathrm{R}_{2}=$ restrição protéica $)$ e temperatura ambiente $\left(\mathrm{T}_{1}=18^{\circ} \mathrm{C} ; \mathrm{T}_{2}=25^{\circ} \mathrm{C} ; \mathrm{T}_{3}=33^{\circ} \mathrm{C}\right)$. Do $8^{\circ}$ ao $14^{\circ}$ dia, os frangos foram submetidos à restrição energética $(2565 \mathrm{kcal}$ de EM/kg e $20 \%$ de proteína bruta) ou protéica $(2850 \mathrm{kcal}$ de $\mathrm{EM} / \mathrm{kg}$ e $15 \%$ de proteína bruta), sendo, posteriormente, alimentados à vontade. A restrição protéica resultou em menor ganho de peso e menor diâmetro do fêmur no $14^{\circ}$ dia de idade. Não foram observadas diferenças nessas características a partir do $21^{\circ}$ dia de idade. $\mathrm{O}$ ganho de peso e o crescimento do fêmur não foram influenciados pela restrição energética. A alta temperatura ambiente $\left(33^{\circ} \mathrm{C}\right)$ influenciou negativamente o ganho de peso e o diâmetro do fêmur, a partir do $21^{\circ}$ dia, e o comprimento do fêmur, no $42^{\circ}$ dia de idade. Tanto a restrição protéica, na segunda semana, quanto a alta temperatura ambiente, a partir do $21^{\circ}$ dia de idade, reduziram o ganho de peso e o crescimento do fêmur de frangos.
\end{abstract}

Palavras-chave: frango de corte, desempenho, energia, programa alimentar, proteína.

\begin{abstract}
The effect of protein or energy restriction during the second week post-hatching on body weight gain and femur development of broiler chickens reared at different environmental temperatures $\left(18^{\circ} \mathrm{C}, 25^{\circ} \mathrm{C}\right.$ and $33^{\circ} \mathrm{C}$ ) was studied. From 1 to 7 days of age and after a restriction period broilers were fed on a control diet with $2850 \mathrm{kcal} \mathrm{ME} / \mathrm{kg}$ and $20 \%$ crude protein. From 8 to 14 days of age, two groups of broilers were fed on restricted energy and protein diets with $2565 \mathrm{kcal} \mathrm{ME} / \mathrm{kg}$ and $20 \%$ of crude protein or $2850 \mathrm{kcal}$ ME/kg and 15\% of crude protein, respectively. At 14,21,28, 35 and 42 days, the bones were weighed and the length and width of bones measured. The protein restriction reduced the body weight gain and the diameter of bone at second week of life. After 21 days of age no differences between treatments for these traits were observed. The body weight gain and femur growth were not affected by energy restriction. The high temperature $\left(33^{\circ} \mathrm{C}\right)$ reduced weight gain and femur diameter from 21 to 42 days of age, and femur length at 42 days of age. The protein restriction at second week or the high environmental temperature after $21^{\text {st }}$ day of life decreased body weight gain and femur growth of broiler chickens.
\end{abstract}

Keywords: broiler chick, bone growth, feed restriction, temperature

Recebido para publicação em 15 de novembro de 2003

Recebido para publicação, após modificações, em 17 de julho de 2004

*Autor para correspondência (corresponding author)

E-mail: rlfurlan@fcav.unesp.br 


\section{INTRODUÇÃO}

A seleção genética para ganho de peso e conversão alimentar, aliada à melhor nutrição, resultou em linhagens de frangos de corte com alta produtividade. Trabalhos têm mostrado que o rápido crescimento foi acompanhado pelo aumento de anomalias no tecido esquelético das aves, principalmente em ossos longos (Leach e Lilburn, 1993; Sullivan, 1994). Técnicas de manejo foram sugeridas para minimizar o risco do surgimento de problemas no crescimento dos ossos. Uma delas envolve a restrição alimentar precoce (Robinson et al., 1992), com subseqüente ganho compensatório, alcançando o peso de mercado na idade de abate (Lilburn, 1994).

Há dois tipos de restrição alimentar: qualitativa, caracterizada pela diminuição de determinado nutriente na ração, e quantitativa, quando a ingestão de alimento é reduzida, mantendo-se os níveis dos nutrientes na ração. Lilburn (1994) observou efeitos negativos no crescimento ósseo, quando a dieta apresentava deficiência em energia. Leterrier et al. (1998) mostraram que a restrição energética ocasionava diminuição na taxa de crescimento, sem afetar a qualidade óssea. Dicle et al. (1998) também não verificaram alterações nas características ósseas em aves alimentadas com menor teor protéico.

Além do fator nutricional, o efeito agudo ou crônico do ambiente onde o animal se encontra deve ser levado em consideração. Segundo Murakami (2000), a incidência de anormalidades de crescimento é aumentada pelo estresse ambiental. Bruno et al. (2000) observaram redução no crescimento de ossos longos em frangos criados em altas temperaturas, enquanto Yalçin et al. (1996) não encontraram efeito da temperatura ambiente sobre o crescimento longitudinal da tíbia e úmero em frangos de corte.

O objetivo deste trabalho foi investigar o efeito da restrição alimentar qualitativa, protéica ou energética sobre o ganho de peso e crescimento ósseo de frangos de corte criados em diferentes temperaturas ambiente.

\section{MATERIAL E MÉTODOS}

Foram utilizados 900 pintainhos de corte machos, de um dia de idade, da linhagem comercial Ross. Do primeiro ao sétimo dia de vida, todas as aves foram mantidas em $33^{\circ} \mathrm{C}$. No oitavo dia, as aves foram pesadas e alojadas em três câmaras climatizadas nas temperaturas de $18^{\circ} \mathrm{C}, 25^{\circ} \mathrm{C}$ e $33^{\circ} \mathrm{C}$, com variação de $\pm 2^{\circ} \mathrm{C}$, onde permaneceram até o $42^{\circ}$ dia de idade. Cada câmara climática era constituída por 12 boxes com nove aves $/ \mathrm{m}^{2}$, separados entre si por tela de arame galvanizado, medindo cada boxe $2,50 \mathrm{~m}$ de comprimento $\mathrm{x} 1,10 \mathrm{~m}$ de largura. Para se obter a temperatura desejada, foram utilizados aquecedores elétricos e monoblocos frigorífico controlados por termostatos.

As dietas foram formuladas tendo como ingredientes básicos milho e farelo de soja, adicionados de suplementos vitamínico-minerais e promotores de crescimento (Tab. 1). Dentro de cada temperatura ambiente, nos sete primeiros dias de vida, todas as aves receberam ração à vontade, contendo $2850 \mathrm{kcal}$ de $\mathrm{EM} / \mathrm{kg}$ de ração e $20 \%$ de PB. Do oitavo ao $14^{\circ}$ dia de vida, as aves foram arraçoadas com um dos três tipos de dietas: o grupo-controle recebeu $2850 \mathrm{kcal}$ de $\mathrm{EM} / \mathrm{kg}$ de ração e $20 \%$ de $\mathrm{PB}$ (relação energia $(\mathrm{E})$ :proteína $(\mathrm{P})=142,50)$; o grupo submetido à restrição energética, $2565 \mathrm{kcal}$ de $\mathrm{EM} / \mathrm{kg}$ de ração e $20 \%$ de $\mathrm{PB}(\mathrm{E}: \mathrm{P}=128,25)$ e o grupo submetido à restrição protéica, $2850 \mathrm{kcal}$ de $\mathrm{EM} / \mathrm{kg}$ de ração e $15 \%$ de $\mathrm{PB}(\mathrm{E}: \mathrm{P}=190,00)$. Após o período de restrição, do $15^{\circ}$ ao $21^{\circ}$ dia de idade, todos os grupos receberam ração à vontade contendo 2850 $\mathrm{kcal}$ de EM/kg de dieta e $20 \%$ de PB. Na fase final (22-42 dias de idade) para os três grupos, foi utilizada ração contendo $3040 \mathrm{kcal}$ de EM/kg e $17 \%$ de $\mathrm{PB}(\mathrm{E}: \mathrm{P}=178,82)$.

No $14^{\circ}, 21^{\circ}, 28^{\circ}$ e $42^{\circ}$ dias de idade, as aves foram pesadas para avaliação do ganho de peso. Foram retiradas ao acaso oito aves de cada tratamento, as quais foram sacrificadas por deslocamento cervical para retirada do fêmur da perna direita. Foram medidos o comprimento longitudinal e o diâmetro, na parte média do osso, com o auxílio de um paquímetro. 
Efeito da temperatura ambiente...

Tabela 1. Composição percentual e nível nutricional das dietas experimentais para frangos de corte

\begin{tabular}{|c|c|c|c|c|}
\hline Ingrediente (\%) & Dieta 1 & Dieta 2 & Dieta 3 & Dieta 4 \\
\hline Milho moído & 61,750 & 52,607 & 66,500 & 61,750 \\
\hline Farelo de soja & 31,946 & 33,637 & 20,741 & 25,750 \\
\hline Óleo de soja & 0,129 & 0,000 & 1,193 & 3,901 \\
\hline Caulim & 1,175 & 8,756 & 6,566 & 3,599 \\
\hline Núcleo $^{1}$ & 5,000 & 5,000 & 5,000 & 5,000 \\
\hline \multicolumn{5}{|c|}{ Composição calculada } \\
\hline Proteína bruta (\%) & 20 & 20 & 15 & 17 \\
\hline Energia metabolizável (kcal/kg) & 2850 & 2565 & 2850 & 3040 \\
\hline Metionina (\%) & 0,419 & 0,415 & 0,352 & 0,378 \\
\hline Metionina + Cistina (\%) & 0,651 & 0,642 & 0,515 & 0,566 \\
\hline Lisina $(\%)$ & 1,059 & 1,086 & 0,748 & 0,881 \\
\hline Cálcio (\%) & 1,007 & 1,012 & 0,968 & 0,985 \\
\hline P disponível (\%) & 0,390 & 0,385 & 0,374 & 0,379 \\
\hline
\end{tabular}

${ }^{1}$ Suplemento vitamínico-mineral. Quantidade suprida por kg do produto (núcleo): vitamina $\mathrm{A} 176.000 \mathrm{UI}$, vitamina $\mathrm{D}_{3} 40.000 \mathrm{UI}$, vitamina E 500mg; vitamina $K_{3} 100 \mathrm{mg}$, vitamina $B_{1} 36 \mathrm{mg}$, vitamina $B_{2} 200 \mathrm{mg}$, vitamina $B_{6} 50 \mathrm{mg}$, vitamina $B_{12} 560 \mathrm{mcg}$, niacina $700 \mathrm{mg}$, biotina $3 \mathrm{mg}$, ácido pantotênico $500 \mathrm{mg}$, ácido fólico $30 \mathrm{mg}$, colina $20 \mathrm{~g}$, ferro $1.100 \mathrm{mg}$, cobre $300 \mathrm{mg}$, manganês $1.800 \mathrm{mg}$, zinco $1.200 \mathrm{mg}$, iodo $24 \mathrm{mg}$, selênio $3 \mathrm{mg}$, metionina $20 \mathrm{~g}$, cálcio $176 \mathrm{~g}$, fósforo $68 \mathrm{~g}$, sódio $23 \mathrm{~g}$, cloro $36 \mathrm{~g}$, coccidiostático $10 \mathrm{~g}$, antioxidante $1 \mathrm{~g}$, excipiente (qsp) $1.000 \mathrm{~g}$.

O experimento foi desenvolvido segundo um delineamento inteiramente ao acaso, disposto em esquema fatorial $3 \times 3$ (restrição alimentar: $\mathrm{R}_{0}=$ ad libitum, $\mathrm{R}_{1}=$ restrição energética e $\mathrm{R}_{2}=$ restrição protéica; e temperatura ambiente: $\mathrm{T}_{1}=$ $18^{\circ} \mathrm{C}, \mathrm{T}_{2}=25^{\circ} \mathrm{C}$ e $\mathrm{T}_{3}=33^{\circ} \mathrm{C}$ ), totalizando nove tratamentos com quatro repetições de 25 aves. As análises de variância foram realizadas por meio do procedimento GLM do SAS $^{\circledR}$ (User's..., 2002). Para verificar a significância entre as médias dos tratamentos, foi utilizado o teste Tukey com nível de 5\% de probabilidade.

\section{RESULTADOS}

Não foi observada interação $(\mathrm{P}>0,05)$ entre restrição alimentar e temperatura ambiente, evidenciando, assim, que os efeitos das variáveis sobre o ganho de peso dos frangos agiram de forma independente. A restrição energética não afetou $(\mathrm{P}>0,05)$ o ganho de peso dos frangos de corte (Tab. 2). Já a restrição protéica reduziu o ganho de peso das aves no período de 8-14 dias de idade; no entanto, a partir do $21^{\circ}$ dia (sete dias após o fornecimento de dieta normal), não foram observadas diferenças $(\mathrm{P}>0,05)$ entre os tratamentos. Ao final do período experimental (42 dias), não se observou diferença $(\mathrm{P}>0,05)$ entre os tratamentos quanto ao peso dos frangos. A temperatura ambiente elevada $\left(33^{\circ} \mathrm{C}\right)$ reduziu $(\mathrm{P}<0,05)$ o ganho de peso dos frangos de corte a partir do $21^{\circ}$ dia de idade, quando comparado com os ganhos à temperatura de $25^{\circ} \mathrm{C}$ ou $18^{\circ} \mathrm{C}$ (Tab. 2).

O diâmetro do fêmur (Tab. 3) foi influenciado pela restrição protéica $(\mathrm{P}<0,05)$, mas não pela energética $(\mathrm{P}>0,05)$. $\mathrm{O}$ efeito foi significativo somente no período de restrição das aves. A alta temperatura ambiente, a partir do período de 15 21 dias de idade, reduziu $(\mathrm{P}<0,05)$ o diâmetro do fêmur dos frangos, quando comparado com os frangos criados a $25^{\circ} \mathrm{C}$ ou $18^{\circ} \mathrm{C}$.

A restrição alimentar protéica reduziu $(\mathrm{P}<0,05)$ o comprimento do fêmur das aves somente ao final do período de restrição (8-14 dias de vida); a partir do período de 15-21 dias de idade, não foi verificado efeito sobre essa variável (Tab. 4). A temperatura ambiente quente mostrou-se efetiva em reduzir $(\mathrm{P}<0,05)$ o comprimento do fêmur somente na fase final do período experimental (29-42 dias de vida). Os efeitos de temperatura ambiente e da restrição alimentar, energética ou protéica sobre o comprimento do fêmur também se mostraram independentes, não se observando interação $(\mathrm{P}>0,05)$.

A Tab. 5 mostra os coeficientes de correlação entre o ganho de peso e o diâmetro ou comprimento do fêmur para aves submetidas à restrição energética ou protéica. Ao final do período de restrição (8-14 dias), não se observou correlação significativa entre as variáveis, exceto entre ganho de peso e comprimento do fêmur na 
restrição energética. Aos 42 dias de idade, a correlação foi positiva entre as características estudadas, independente do programa alimentar.

A Tab. 6 apresenta os coeficientes de correlação entre o ganho de peso e o diâmetro ou comprimento do fêmur para aves submetidas a diferentes temperaturas ambiente. Foi observada correlação entre ganho de peso e diâmetro do fêmur, no final do período de restrição, nas aves submetidas à temperatura de $18^{\circ} \mathrm{C}$. Aos 42 dias de idade, a correlação entre ganho de peso e comprimento do fêmur foi positiva em todas as temperaturas estudadas.

Tabela 2. Ganho de peso $(\mathrm{g})$ de frangos submetidos à restrição alimentar qualitativa energética ou protéica, entre $8-14$ dias de idade, à temperaturas de $18^{\circ} \mathrm{C}, 25^{\circ} \mathrm{C}$ ou $33^{\circ} \mathrm{C}$, em diferentes idades

\begin{tabular}{|c|c|c|c|c|}
\hline \multirow{2}{*}{ Variável } & \multicolumn{4}{|c|}{ Idade (dias) } \\
\hline & $8-14$ & $15-21$ & $22-28$ & $29-42$ \\
\hline \multicolumn{5}{|l|}{ Programa alimentar } \\
\hline Controle ${ }^{1}$ & $283,4 \mathrm{a}$ & $568,8 \mathrm{a}$ & $825,5 \mathrm{a}$ & $1.773,3 \mathrm{a}$ \\
\hline Restrição energética ${ }^{2}$ & $279,3 \mathrm{a}$ & $535,9 \mathrm{a}$ & $864,5 \mathrm{a}$ & $1.643,3 \mathrm{a}$ \\
\hline Restrição protéica ${ }^{3}$ & $237,7 \mathrm{~b}$ & $541,7 \mathrm{a}$ & $856,3 \mathrm{a}$ & $1.679,2 \mathrm{a}$ \\
\hline \multicolumn{5}{|l|}{ Temperatura ambiente } \\
\hline $18^{\circ} \mathrm{C}$ & $277,1 \mathrm{a}$ & $566,7 \mathrm{a}$ & $873,8 \mathrm{a}$ & $1.864,6 \mathrm{a}$ \\
\hline $25^{\circ} \mathrm{C}$ & $263,8 \mathrm{a}$ & $587,2 \mathrm{a}$ & $918,7 \mathrm{a}$ & $1.911,7 \mathrm{a}$ \\
\hline $33^{\circ} \mathrm{C}$ & $259,4 \mathrm{a}$ & $492,5 b$ & $780,8 \mathrm{~b}$ & $1.319,6 \mathrm{~b}$ \\
\hline \multicolumn{5}{|l|}{ Valores de F } \\
\hline Programa alimentar (PA) & $11,05^{* *}$ & $1,11 \mathrm{~ns}$ & $0,07 \mathrm{~ns}$ & $1,52 \mathrm{~ns}$ \\
\hline Temperatura $(\mathrm{T})$ & $1,47 \mathrm{~ns}$ & $8,92 * *$ & $8,76^{* *}$ & $36,56 * *$ \\
\hline Interação PA X T & $0,95 \mathrm{~ns}$ & $0,37 \mathrm{~ns}$ & $2,11 \mathrm{~ns}$ & $0,22 \mathrm{~ns}$ \\
\hline $\mathrm{CV}(\%)$ & 9,8 & 10,5 & 9,5 & 11,1 \\
\hline
\end{tabular}

Para cada variável, médias seguidas por letras diferentes, na coluna, diferem entre si pelo teste Tukey.

$* *(\mathrm{P}<0,01)$; ns $(\mathrm{P}>0,05)$.

${ }^{1}$ Ad libitum (2.850 kcal EM/kg e $20 \%$ proteína bruta).

${ }^{2}$ Restrição energética ( $2.565 \mathrm{kcal}$ de EM/kg e $20 \%$ proteína bruta do $8^{\circ}$ ao $14^{\circ}$ dias de idade).

${ }^{3}$ Restrição protéica $\left(2.850 \mathrm{kcal} \mathrm{EM} / \mathrm{kg}\right.$ e $15 \%$ proteína bruta do $8^{\circ}$ ao $14^{\circ}$ dias de idade).

Tabela 3. Diâmetro do fêmur $(\mathrm{mm})$ de frangos submetidos à restrição alimentar qualitativa energética ou protéica, entre $8-14$ dias de idade, a temperaturas de $18^{\circ} \mathrm{C}, 25^{\circ} \mathrm{C}$ ou $33^{\circ} \mathrm{C}$, em diferentes idades

\begin{tabular}{|c|c|c|c|c|}
\hline \multirow{2}{*}{ Variável } & \multicolumn{4}{|c|}{ Idade (dias) } \\
\hline & $8-14$ & $15-21$ & $22-28$ & $29-42$ \\
\hline \multicolumn{5}{|l|}{ Programa alimentar } \\
\hline Controle $^{1}$ & $4,31 \mathrm{a}$ & $5,64 a$ & $6,74 a$ & $9,41 \mathrm{a}$ \\
\hline Restrição energética $^{2}$ & $4,26 \mathrm{a}$ & $5,63 a$ & $6,79 a$ & $9,21 \mathrm{a}$ \\
\hline Restrição protéica ${ }^{3}$ & $3,93 b$ & $5,48 \mathrm{a}$ & $6,78 \mathrm{a}$ & $9,46 a$ \\
\hline \multicolumn{5}{|l|}{ Temperatura ambiente } \\
\hline $18^{\circ} \mathrm{C}$ & $4,25 \mathrm{a}$ & $5,85 a$ & $6,86 a$ & $9,67 \mathrm{a}$ \\
\hline $25^{\circ} \mathrm{C}$ & $4,22 \mathrm{a}$ & $5,71 \mathrm{a}$ & $6,94 a$ & $9,76 a$ \\
\hline $33^{\circ} \mathrm{C}$ & $4,03 a$ & $5,20 \mathrm{~b}$ & $6,21 b$ & $8,63 b$ \\
\hline \multicolumn{5}{|l|}{ Valores de F } \\
\hline Programa alimentar (PA) & $5,42 *$ & $0,79 \mathrm{~ns}$ & $0,04 \mathrm{~ns}$ & $0,78 \mathrm{~ns}$ \\
\hline Temperatura (T) & $1,66 \mathrm{~ns}$ & $11,83 * *$ & $12,85 * *$ & $21,37 * *$ \\
\hline Interação PA X T & $0,85 \mathrm{~ns}$ & $0,70 \mathrm{~ns}$ & $0,43 n s$ & $0,18 \mathrm{~ns}$ \\
\hline $\mathrm{CV}(\%)$ & 7,5 & 6,2 & 6,8 & 5,0 \\
\hline
\end{tabular}

Para cada variável, médias seguidas por letras diferentes, na coluna, diferem entre si pelo teste Tukey.

$*(\mathrm{P}<0,05) ; * *(\mathrm{P}<0,01) ; \mathrm{ns}(\mathrm{P}>0,05)$.

${ }_{1}^{1}$ Ad libitum $(2.850 \mathrm{kcal}$ EM/kg e $20 \%$ proteína bruta).

${ }^{2}$ Restrição energética ( $2.565 \mathrm{kcal}$ de EM $/ \mathrm{kg}$ e $20 \%$ proteína bruta do $8^{\circ}$ ao $14^{\circ}$ dias de idade).

${ }^{3}$ Restrição protéica $\left(2.850 \mathrm{kcal}\right.$ EM/kg e $15 \%$ proteína bruta do $8^{\circ}$ ao $14^{\circ}$ dias de idade). 
Efeito da temperatura ambiente...

Tabela 4. Comprimento do fêmur $(\mathrm{mm})$ de frangos submetidos à restrição alimentar qualitativa energética ou protéica, entre $8-14$ dias de idade, a temperaturas de $18^{\circ} \mathrm{C}, 25^{\circ} \mathrm{C}$ ou $33^{\circ} \mathrm{C}$, em diferentes idades

\begin{tabular}{lcccc}
\hline \multirow{2}{*}{ Variável } & \multicolumn{4}{c}{ Idade (dias) } \\
\cline { 2 - 4 } & $8-14$ & $15-21$ & $22-28$ & $29-42$ \\
\hline Programa alimentar $^{\text {Controle }}$ & & & & \\
Restrição energética $^{2}$ & $42,60 \mathrm{a}$ & $52,81 \mathrm{a}$ & $59,60 \mathrm{a}$ & $74,17 \mathrm{a}$ \\
Restrição protéica $^{3}$ & $42,02 \mathrm{a}$ & $52,06 \mathrm{a}$ & $60,25 \mathrm{a}$ & $71,52 \mathrm{a}$ \\
Temperatura ambiente & $40,88 \mathrm{~b}$ & $52,15 \mathrm{a}$ & $60,08 \mathrm{a}$ & $73,13 \mathrm{a}$ \\
$18^{\circ} \mathrm{C}$ & & & & \\
$25^{\circ} \mathrm{C}$ & $41,61 \mathrm{a}$ & $51,82 \mathrm{a}$ & $58,83 \mathrm{a}$ & $73,99 \mathrm{a}$ \\
$33^{\circ} \mathrm{C}$ & $42,03 \mathrm{a}$ & $53,15 \mathrm{a}$ & $60,70 \mathrm{a}$ & $76,23 \mathrm{a}$ \\
Valores de F & $41,85 \mathrm{a}$ & $52,06 \mathrm{a}$ & $60,48 \mathrm{a}$ & $68,58 \mathrm{~b}$ \\
Programa alimentar (PA) & & & \\
Temperatura (T) & $13,24^{* *}$ & $0,61 \mathrm{~ns}$ & $0,13 \mathrm{~ns}$ & $3,01 \mathrm{~ns}$ \\
Interação PA X T & $0,19 \mathrm{~ns}$ & $1,82 \mathrm{~ns}$ & $2,84 \mathrm{~ns}$ & $24,88^{* *}$ \\
CV (\%) & $1,77 \mathrm{~ns}$ & $0,79 \mathrm{~ns}$ & $2,82 \mathrm{~ns}$ & $1,47 \mathrm{~ns}$ \\
\hline
\end{tabular}

Para cada variável, médias seguidas por letras diferentes, na coluna, diferem entre si pelo teste Tukey.

** $(\mathrm{P}<0,01)$; ns $(\mathrm{P}>0,05)$

${ }^{1}$ Ad libitum (2.850 kcal EM/kg e $20 \%$ proteína bruta).

${ }^{2}$ Restrição energética $\left(2.565 \mathrm{kcal}\right.$ de EM/kg e $20 \%$ proteína bruta do $8^{\circ}$ ao $14^{\circ}$ dias de idade).

${ }^{3}$ Restrição protéica ( $2.850 \mathrm{kcal} \mathrm{EM} / \mathrm{kg}$ e $15 \%$ proteína bruta do $8^{\circ}$ ao $14^{\circ}$ dias de idade).

Tabela 5. Coeficientes de correlação entre ganho de peso do frango $(\mathrm{g})$ e diâmetro $(\mathrm{mm})$ ou comprimento $(\mathrm{mm})$ do fêmur de frangos de corte nas diferentes idades e programas alimentares

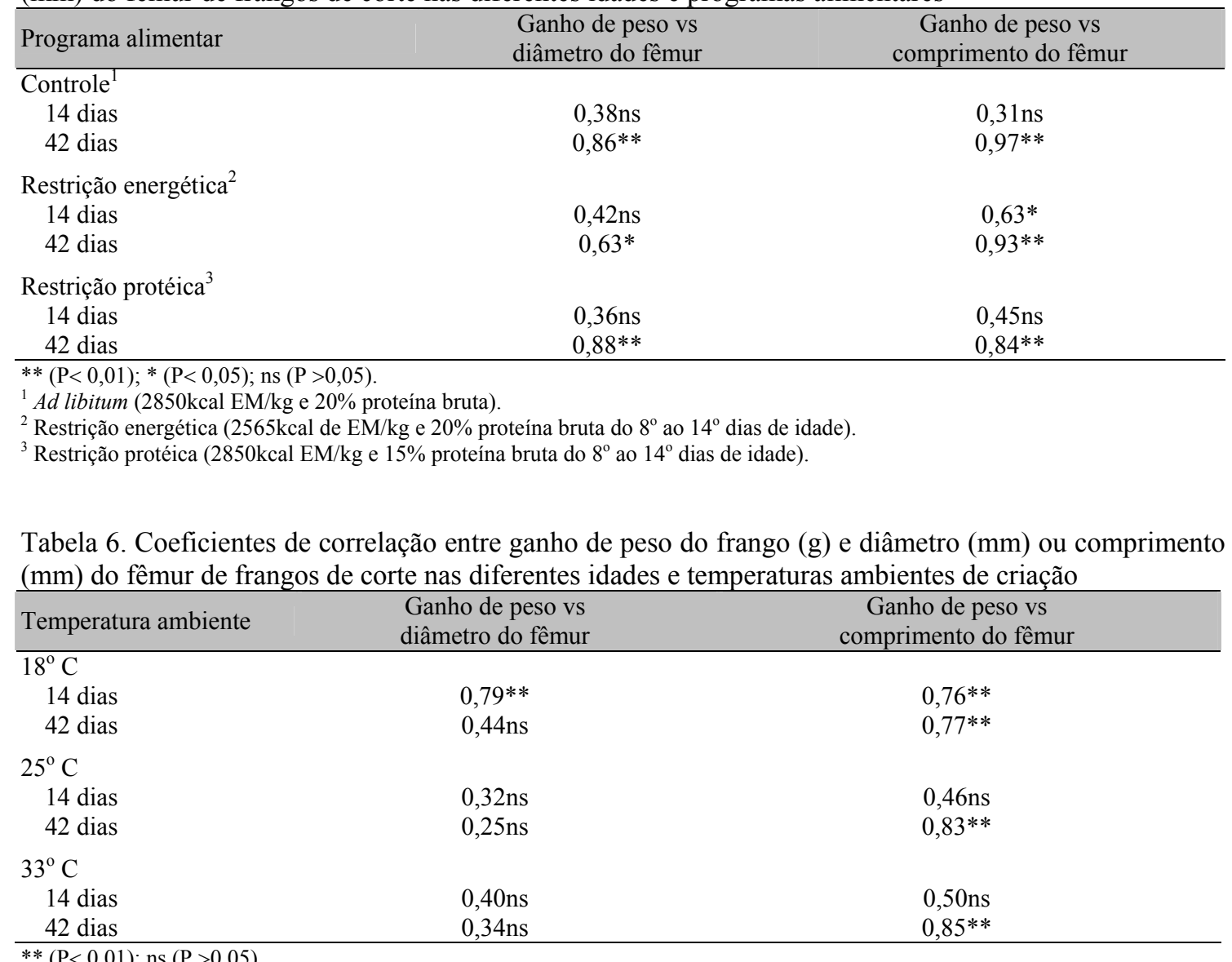




\section{DISCUSSÃO}

Os programas de restrição alimentar utilizados para frangos de corte têm produzido uma variedade de respostas em termos de crescimento ou ganho compensatório. Plavnik e Hurwitz (1985) e Zubair e Leeson (1994) sugeriram ganho compensatório para aves realimentadas após um período de restrição alimentar quantitativa. Cabel e Waldroup (1990) e Robinson et al. (1992) não observaram o efeito de ganho compensatório após um período de restrição alimentar qualitativa. Essas diferenças de achados podem ser atribuídas à severidade, duração da restrição alimentar, linhagem e sexo tendo em vista que esses fatores podem afetar a habilidade dos frangos em recuperar o seu peso (Yu e Robinson, 1992).

Segundo Nestor (1984), o potencial para rápido ganho de peso dos frangos das linhagens atuais pode ser considerado como uma das principais causas das anormalidades de pernas. Assim, a utilização de programas de restrição alimentar, visando à perfeita adequação do sistema esquelético para suportar na fase final de crescimento o peso da massa muscular e visceral, tem sido sustentada por autores, como Leeson e Summers (1984) e Leterrier et al. (1998). Os resultados deste trabalho mostraram que a restrição alimentar protéica reduziu o ganho de peso ao final do período de restrição, porém não foram observadas diferenças entre os tratamentos ao final do período experimental, evidenciando, assim, ganho compensatório. Ferket e Sell (1989), ao trabalharem com restrição alimentar protéica em perus, observaram limitada habilidade em compensar o ganho de peso na primeira semana de realimentação. Furlan (1996), ao trabalhar com restrição alimentar quantitativa, verificou que, apesar de os frangos apresentarem um potencial crescimento na semana subseqüente à realimentação, o período de uma semana era insuficiente para que os frangos com restrição apresentassem ganho compensatório e alcançassem o peso das aves controle.

Assim como a proteína, o teor de energia da ração é fator importante no desenvolvimento das aves. Bruno (2002) observou que frangos submetidos à restrição alimentar qualitativa energética apresentaram peso corporal significativamente menor, quando comparados com frangos restritos em proteína. No entanto, neste experimento, a restrição energética imposta não foi severa a ponto de prejudicar o ganho de peso das aves. Giachetto et al. (2003) também não encontraram diferenças no peso vivo entre frangos alimentados com alta ou baixa energia. Essa diversidade de resultados pode estar relacionada ao tempo e ao nível de restrição utilizado nos diferentes experimentos.

Neste experimento, os dados mostraram que a utilização de programas de restrição alimentar qualitativa protéica é capaz de alterar o padrão de desenvolvimento do tecido ósseo (diâmetro e comprimento) em frangos, e que, ao restabelecer os níveis normais de proteína com a realimentação, ocorreu crescimento compensatório do fêmur, e que aos 42 dias de idade já não havia diferença no tamanho do fêmur (diâmetro e comprimento). Kirn e Firman (1993) e Yalçin et al. (1998), ao trabalharem com vários níveis de proteína na dieta para perus e frangos de corte, respectivamente, encontraram resultados similares ao deste estudo. Hester et al. (1990) sugeriram que a variação nos níveis de proteína da dieta pode contribuir para reduzir a resistência dos ossos, e Massey (1998), ao comparar o efeito de dietas com alto ou baixo teor protéico, em humanos, observou menor perda urinária de cálcio na dieta com baixo teor protéico. Visando avaliar os efeitos da suplementação com aminoácidos na dieta sobre o desenvolvimento ósseo, Skinner et al. (1991) verificaram a existência de interação entre os níveis de aminoácidos e de cálcio da dieta com efeito sobre o teor de cinzas, peso e comprimento da tíbia em frangos.

Além da dieta, outros fatores, como a temperatura ambiente, também podem afetar o crescimento dos ossos. Hester (1994) mostrou que altas temperaturas ambientais predispõem as aves à anormalidade das pernas. Bruno et al. (2002) relataram que a restrição alimentar qualitativa, associada a altas temperaturas, é capaz de reduzir o crescimento de ossos longos em frangos de corte. Resultados semelhantes foram obtidos por Bruno et al. (2000) utilizando restrição alimentar quantitativa. Entretanto, Yalçin et al. (1996) verificaram que alta temperatura ambiente reduz o peso, mas não o crescimento da tíbia e do úmero. Neste experimento, a alta temperatura ambiente imposta reduziu tanto o diâmetro quanto o 
comprimento do fêmur. Em ambientes quentes, devido à baixa capacidade de perda calórica, o frango desenvolve hipertermia e, como conseqüência, reduz o consumo de alimento. Essa redução de consumo poderia ser fator determinante em diminuir o ganho de peso e o crescimento ósseo, pois, além de comprometer os processos de absorção de minerais, a falta de nutrientes poderia atuar como fator de restrição à osteogênese. Outra hipótese estaria no fato de que o estresse calórico poderia induzir alcalose respiratória, levando a uma maior complexação do cálcio pelas proteínas do sangue, tornando-o, portanto, indisponível para o osso. Os baixos níveis de dióxido de carbono, durante a alcalose respiratória, favorecem também a dissolução de cristais de apatita no osso, tendo, portanto, um reflexo direto no processo de desenvolvimento ósseo (Bushinky e Sessler, 1992).

Conclui-se que a restrição protéica, na segunda semana de vida, e a alta temperatura ambiente, a partir de 21 dias de idade, são capazes de reduzir o ganho de peso e o crescimento ósseo (diâmetro e o comprimento) do fêmur de frangos de corte.

\section{AGRADECIMENTO}

Os autores agradecem a Fundação de Amparo à Pesquisa do Estado de São Paulo (FAPESP) pelo suporte financeiro.

\section{REFERÊNCIAS BIBLIOGRÁFICAS}

BRUNO, L.D.G. Desenvolvimento ósseo em frangos: influência da restrição alimentar e da temperatura ambiente. 2002. 77f. Tese (Doutorado) - Faculdade de Ciências Agrárias e Veterinárias, Universidade Estadual Paulista, Jaboticabal, São Paulo.

BRUNO, L.D.G.; FURLAN, R.L., MALHEIROS, E.B. et al. Influence of early quantitative food restriction on long bone growth at different environmental temperatures in broiler chickens. Br. Poult. Sci., v.41, p.389-394, 2000.

BUSHINSKY, D.A.; SESSLER, N.E. Critical role of bicarbonate in calcium release from bone. Am. J. Physiol., v.253, p.425-431, 1992.

CABEL, M.C.; WALDROUP, P.W. Effect of different nutrient-restriction programs early in life on broiler performance and abdominal fat content. Poult. Sci., v.69, p.652-660, 1990.

DICLE, O.; YALÇIN, S.; SETTAR, P. Influence of dietary protein and sex on walking ability and bone parameters of broilers. Br. Poult. Sci., v.39, p.251-256, 1998.

FERKET, P.R.; SELL, J.L. Effect of severity of early protein restriction on large turkeys toms. 2 . Carcass characteristics. Poult. Sci., v.68, p.687697, 1989.

FURLAN, R.L. Efeito da restrição alimentar sobre o crescimento e composição da carcaça de frangos de corte. 1996. 102f. Tese (Doutorado) Faculdade de Ciências Agrárias e Veterinárias, Universidade Estadual Paulista, Jaboticabal, SP.

GIACHETTO, P.F., GUERREIRO, E.N., FERRO, J.A. et al. Performance and hormonal profile in broiler chickens fed with different energy levels during post restriction period . Pesq. Agropec. Bras., v.38, p.697-702, 2003.

HESTER, P.Y. The role of environment and management on leg abnormalities in meat-type fowl. Poult. Sci., v.73, p.904-915, 1994.

HESTER, P.Y.; KRUEGER, K.K.; JACKSON, M. The effect of restrictive and compensatory growth on the incidence of leg abnormalities and performance of commercial male turkeys. Poult. Sci., v. 69, p. 1731-1742, 1990.

KIRN, B.N.; FIRMAN, J.D. Leg strength and performance of large white tom turkeys fed various protein and energy levels. Avian Dis., v.37, p.37-46, 1993.

LEACH, R.M.; LILBURN, M.S. Current knowledge on the etiology of tibial dyschondroplasy in the avian species. Poult. Sci., v.4, p.57-65, 1993.

LEESON, S.; SUMMERS, J.D. Influence of nutritional modification on skeletal size of leghorn and broiler breeder pullets. Poult. Sci., v.63, p.1222-1228, 1984.

LETERRIER, C.; ROSE, N.; CONSTANTIN, P. et al. Reducing growth rate of broiler chickens with a low energy diet does not improve cortical bone quality. Br. Poult. Sci., v.39, p.24-30, 1998.

LILBURN, M.S. Skeletal growth of commercial poultry species. Poult. Sci., v.73, p.897-903, 1994. 
MASSEY, L.K. Does excess dietary protein adversely affect bone? In: SYMPOSIUM OVERVIEW, 1998. Cincinnati, 1998. p.10481057.

MURAKAMI, A.E. Balanço eletrolítico da dieta e sua influência sobre o desenvolvimento dos ossos de frangos. In: CONFERÊNCIA APINCO DE CIÊNCIA E TECNOLOGIA AVÍCOLAS, 2000, Campinas. Anais...Campinas, 2000. p.3361.

NESTOR, K.E. Genetics of growth and reproduction in the turkey. 9. Long-term selection for increase 16-week body weight. Poult. Sci., v.63, p.2114-2122, 1984.

PLAVINIK, I.; HURWITZ, S. The performance of broiler chicks during and following a severe feed restriction at an early age. Poult. Sci., v.64, p.348-355, 1985.

ROBINSON, F.E.; CLASSEN, H.L.; HANDON, J.A. et al. Growth performance, feed efficiency and the incidence of skeletal and metabolic disease in full-fed and fed restricted broiler and roaster chickens. J. Appl. Poult. Res., v.1, p.3341, 1992.

SKINNER, J.T., BEASLEY, J.N., WALDROUP, P.W. et al. Effects of dietary amino acids levels on bone development in broiler chickens. Poult. Sci., v.70, p.941-946, 1991.

SULLIVAN, T.W. Skeletal problems in poultry: estimated annual cost and descriptions. Poult. Sci., v.73, p.879-882, 1994.

USER'S guide: statistics. Cary, NC: SAS Institute, 2002.

YALÇIN, S.; OZKAN, S.; SETTAR, P. et al. Influence of ambient temperature and genotype on bone parameters and incidence of leg disorders of male and female broilers. WORLD'S POULTRY CONGRESS, 1996, New Delhi, India. Proceedings... New Delhi, India, 1996. v. II, p.577-80.

YALÇIN, S.; SETTAR, P.; DICLE, O. Influence of dietary protein and sex on walking ability and bone parameters of broilers. Br. Poult. Sci., v.39, p.251-256, 1998.

YU, M.W.; ROBINSON, F.E. The application of short-term feed restriction to broilers chickens production: a review. J. Appl.Poult. Res., v.1, p.147-153, 1992.

ZUBAIR, A.K.; LEESON, S. Effect of varying period of early nutrient restriction on growth compensation and carcass characteristics of male broilers. Poult. Sci., v.73, p.129-136, 1994. 